\title{
Combined Effect of a Laser Cladded Coating and Surface Texture on Tribological Performance Under Dry Sliding and Starved Lubrication
}

\author{
Chenfeng Qiao ${ }^{1}$ · Jing Yu ${ }^{2}$ - Shuai Zhang ${ }^{2}$ - Zhengda Liu ${ }^{2}$ Jinlong Wang ${ }^{2}$
}

Received: 26 September 2021 / Accepted: 21 November 2021 / Published online: 6 January 2022

(c) The Author(s) 2022

\begin{abstract}
Fe-based alloy coating was laser cladded on gray cast iron using $\mathrm{Ni}-\mathrm{Cu}$ alloy as an intermediate layer. The cross section of the laser cladded coating was characterized by optical microscopy (OM), scanning electron microscopy (SEM) equipped with energy dispersive spectrometry (EDS), X-ray diffraction (XRD), and a Vickers hardness tester. A microdimple texture was created by reciprocating an electrolyte jet with prefabricated mask (REJP) machining on an Fe-based alloy coating. The tribological performances of untextured and textured coatings were examined through interrupted wear tests using an in-house developed reciprocating ball-on-plate tribotester under dry sliding and starved lubricated conditions. The results show that the presence of microdimple edges in the nonconformal contact region has a detrimental effect on the friction performance under dry sliding. However, the microdimples can be beneficial for trapping debris to preserve a smoother contacting surface and thus a lower volume wear track compared to untextured coatings. Due to its role in oil reservoirs and debris entrapment, the microdimple textured coating can maintain a low friction coefficient for a long time period after lubricant oil cutoff and results in a lower volume wear track under starved lubrication.
\end{abstract}

Keywords Gray cast iron $\cdot$ Laser cladding $\cdot$ Surface texture $\cdot$ Dry sliding $\cdot$ Starved lubrication

\section{Introduction}

Due to its merits, such as good thermal conductivity, mechanical properties and excellent tribological behavior [1], gray cast iron is widely used for manufacturing hydraulic/pneumatic equipment, machine tools, general industrial machines, and transportation equipment [2]. However, the low hardness and brittle fracture feature can seriously threaten their regular operation [3]. Due to its high energy density, laser cladding can be applied to fabricate compact and metallurgically bonded high-quality coatings with a small dilution ratio and low thermal effect on the substrate [4]. However, owing to the high carbon content of gray cast iron, a large number of brittle phases, namely, chilled

Jing $\mathrm{Yu}$

yj.0730.kb@163.com

1 Department of Materials Science and Engineering, Dalian Maritime University, Dalian 116026, China

2 Marine Engineering College, Dalian Maritime University, Dalian 116026, China structures and crack sources, are produced in the interface zone during the welding process. Because nickel can hinder carbon migration and prevent the formation of chilled structures, Ni-based alloy coatings produced by laser cladding on gray cast iron have been extensively studied $[3,5,6]$. However, Ni-based coatings are not a valid sustainable alternative [7] and are expensive. Recently, Fe-based alloys have become attractive because of their low cost, excellent color match and satisfactory hardness. However, limited research [8-10] has demonstrated that it is difficult to directly laser clad Fe-based alloy coatings on gray cast iron, even if preheating of the substrate and/or post clad heat treatment are conducted [11]. Therefore, it is necessary to develop a feasible and facile approach to produce Fe-based alloy coatings on gray cast iron components.

The problem of tribology is always an unavoidable challenge in mechanical systems. Advanced materials and surface texture are the two major research branches for friction reduction [12]. The most widely used texturing techniques are laser surface texturing, microelectric discharge machining and electrochemical texturing [13]. Among these, electrochemical machining technology is a promising option to 
fabricate microtextures using simple equipment, low cost and nonthermal damage on the component surface [14].

In the present study, aiming to reduce the formation of hard and brittle phases at the interface, a Ni-Cu layer with low carbon solubility was fabricated on gray cast iron as an intermediate layer. Then, an Fe-based alloy coating was laser cladded on the intermediate layer. A reciprocating electrolyte jet with prefabricated mask (REJP) machining [15] was employed to generate microdimples on the Fe-based coating. In addition, the tribological performances of the laser cladded coating and the surface textured coating under dry sliding and starved lubrication conditions were investigated.

\section{Experimental Procedure}

\subsection{Materials}

Gray cast iron with dimensions of $\Phi 50 \times 10 \mathrm{~mm}$ was used as the substrate. Gas atomized Fe-based alloy powder ( Fe SP 465 V2) and Ni-Cu alloy powder (1015-00) (Höganäs, Sweden) were used as the coating and intermediate layer materials, respectively. The morphologies and particle size distribution of the two cladding materials are shown in Fig. 1. The chemical compositions of the experimental materials are listed in Table 1.
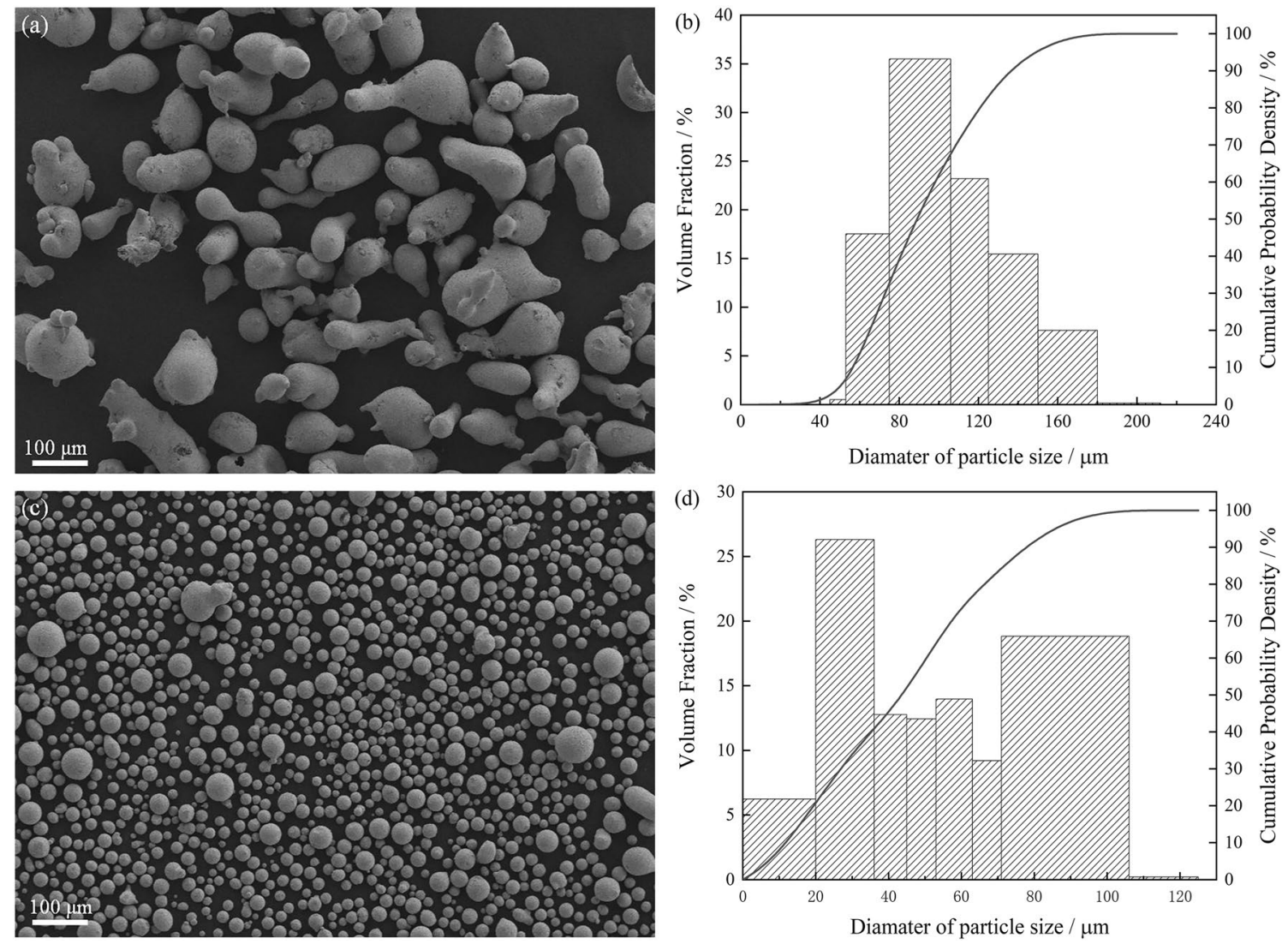

Fig. 1 Characteristics of the laser cladding powder morphology and particle size distribution of Fe-based alloy $\mathbf{a}, \mathbf{b}$ and $\mathrm{Ni}-\mathrm{Cu}$ alloy powder $\mathbf{c}, \mathbf{d}$

Table 1 Chemical composition of the experimental materials $(\mathrm{wt} \%)$

\begin{tabular}{llllllllll}
\hline & $\mathrm{C}$ & $\mathrm{Mo}$ & $\mathrm{Ni}$ & $\mathrm{Fe}$ & $\mathrm{Cr}$ & $\mathrm{Si}$ & $\mathrm{B}$ & $\mathrm{Cu}$ & $\mathrm{Mn}$ \\
\hline Fe SP 465 V2 & 0.14 & 1.04 & 1.47 & $\mathrm{Bal}$ & 15.04 & 0.97 & 1.29 & - & - \\
$1015-00$ & 0.01 & - & $\mathrm{Bal}$ & 0.20 & - & 2.03 & 1.11 & 19.77 & - \\
HT 300 & $2.5-4.0$ & - & - & $\mathrm{Bal}$ & - & $1.0-2.5$ & - & - & $0.5-1.4$ \\
\hline
\end{tabular}




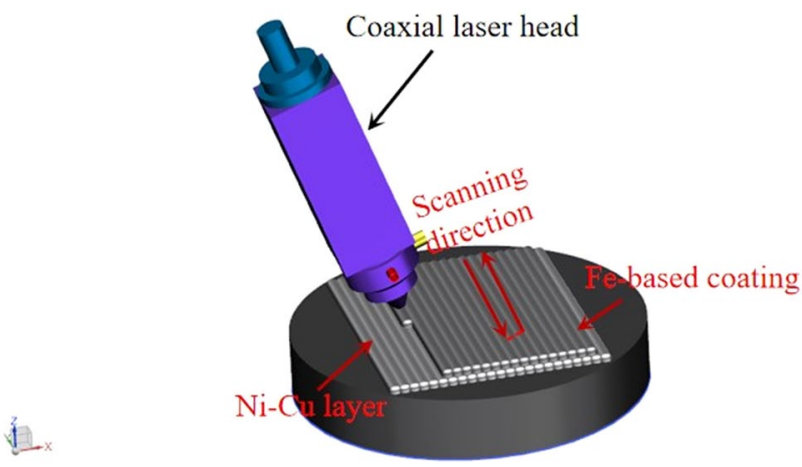

Fig. 2 Laser cladding process

Table 2 Parameters for laser cladding

\begin{tabular}{lll}
\hline & Coating & $\begin{array}{l}\text { Inter- } \\
\text { mediate } \\
\text { layer }\end{array}$ \\
\hline Laser power/W & 1000 & \\
Scanning speed/(mm/s) & 10 & 4 \\
Powder feeding rate/(g/min) & 8.44 & 6.32 \\
Laser spot diameter/mm & 2 & 2 \\
Overlapped width/mm & 0.5 & \\
\hline
\end{tabular}

\subsection{Laser Cladding}

The laser cladding system consists of a semiconductor laser generator (LDF 4000-100), a six degrees of freedom industrial robot (KUKA KR30HA), a coaxial laser head with four nozzles (Precitec YC52), and a double silo negative pressure gas powder feeder (RC-PGF-D, Raycham). Argon served as the powder feeding gas and shielding gas. A schematic of the laser cladding process is shown in Fig. 2. Owing to its high carbon content, gray cast iron is very sensitive to laser cladding parameters. The optimized process parameters are listed in Table 2. The laser scanning path was zigzag, and the scanning directions of the two layers were parallel.

\subsection{Surface Texturing}

The top surface of the laser cladded coating was polished to a roughness of $0.05 \mu \mathrm{m}$ using a CNC milling machine (XY-M100AH, Ruihua Machinery Manufacturing Co. Ltd., China). Microdimples were fabricated on the polished Febased alloy coating by a reciprocating electrolyte jet with a prefabricated mask (REJP) machine. The detailed process of the microtextured surface was illustrated in [14]. The arrangement pattern of microdimples is presented in Fig. 3a. The morphology and cross sectional profile of the textured surface were measured using confocal laser scanning microscopy (CLSM, Olympus LEXT OLS4000), as shown in Fig. 3b. The dimension parameters of the dimple

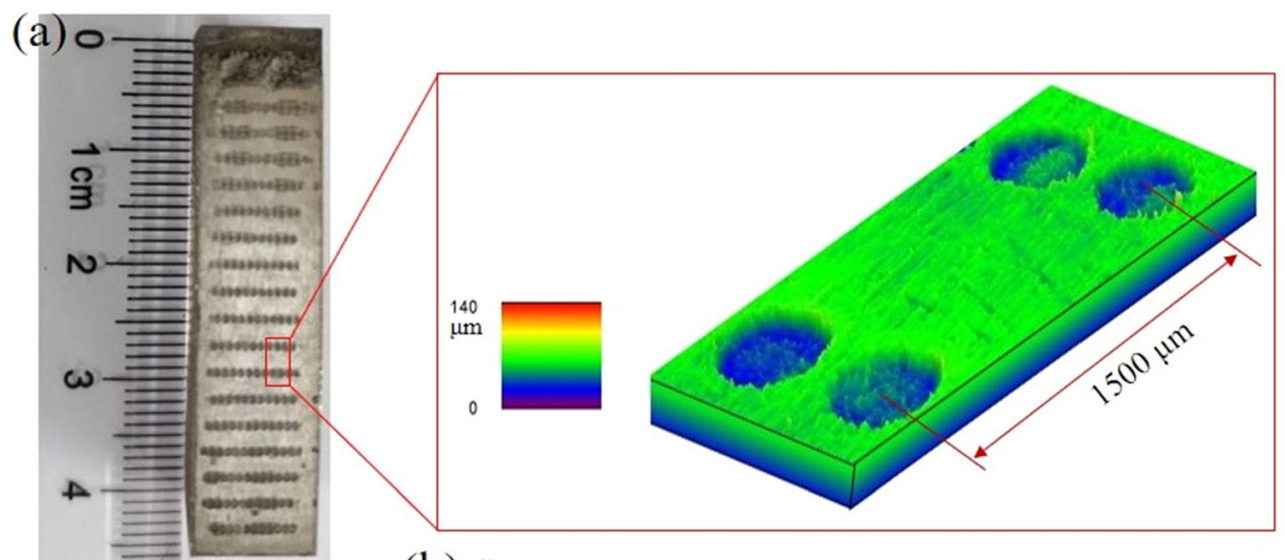

(b)

or

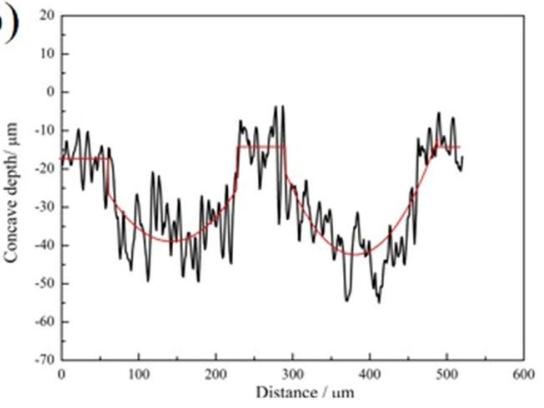

Fig. 3 Photo of the textured coating and 3D topography of the dimples a and a cross sectional profile of the dimples $\mathbf{b}$ 
were approximately $160 \mu \mathrm{m}$ in diameter, $40 \mu \mathrm{m}$ in depth and area ratios of $15.6 \%$.

\subsection{Characterization}

The laser cladded sample was cut perpendicular to the treated surface using wire electrical discharge machining (WEDM, DK 7740, Taizhou CNC Machine Tool Company, China). The cross-section sample was polished by emery paper, then by diamond powder, and finally etched using an aqua regia solution ( $3 \mathrm{HCl}: \mathrm{HNO}_{3}$, volume fraction). The morphology and microstructure of the cross-section were examined by optical microscopy (OM, GX51, OLYMPUS, Tokyo, Japan) and scanning electron microscopy (SEM, ZEISS-SUPRA 55 SAPPHIRE, Oberkochen, Germany) equipped with energy dispersive spectrometry (EDS, Oxford Instruments, Oxford, UK). An X-ray diffractometer (Rigaku Ultima IV) equipped with a $\mathrm{CuK} \alpha \mathrm{X}$-ray source was utilized to examine the phase composition of the top surface of the $\mathrm{Fe}$-based coating and the cross section of the Ni-Cu alloy layer. XRD patterns were taken at $2 \theta$ angles from $10^{\circ}$ to $80^{\circ}$ at a scanning rate of $5 \% \mathrm{~min}$. The hardness of the coating was measured by a Vickers microhardness tester (LW-HV 1000, Beijing Leweiwulian Science and Technology Co., Ltd., Beijing China) with a load of $200 \mathrm{~g}$ and a load dwelling time of $20 \mathrm{~s}$.

\subsection{Friction and Wear Tests}

To comparatively investigate the friction and wear properties of the laser cladded and textured coatings, both dry and starved lubrication sliding tests were carried out using an in-house developed reciprocating ball-on-plate tribotester, as shown in Fig. 4. The counterpart ball was GCr15 with a diameter of $10 \mathrm{~mm}$ and was stationarily fixed by the upper jig and vertically pressed on the lower specimen. The tested specimens were fixed on the lower holder, which was

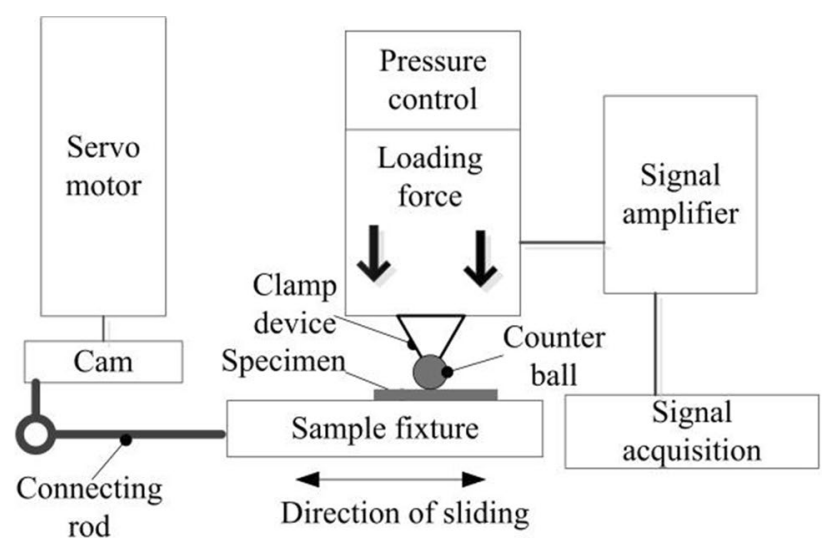

Fig. 4 Schematic of the tribotester reciprocated at a defined speed. The dry sliding tests were conducted under a load of $100 \mathrm{~N}$ at a sliding speed of $0.1 \mathrm{~m} / \mathrm{s}$ and sliding time of $30 \mathrm{~min}$. The starved lubrication tribotests were performed under a load of $200 \mathrm{~N}$ at a sliding speed of $0.1 \mathrm{~m} / \mathrm{s}$. The base oil (CD40 diesel oil) was used as the lubricant. At the beginning of the starved lubrication tests, the oil was supplied at a rate of $0.1 \mathrm{~mL} / \mathrm{min}$, and after $5 \mathrm{~min}$, the oil was cut off. When the friction coefficient increased to a value similar that under dry sliding, the tribotest was ended. The period of time for retaining the stable friction state was recorded to evaluate the tribological performance under starved lubrication.

To examine the worn surface morphology and characterisic of microdimples during different friction stages, it helps to clearly understand the wear process evolution. Thus, interrupted tests were carried out as well. According to the variation of the friction coefficient, two points were selected under dry sliding: (1) the end of running-in stage, and (2) the end of dry sliding test; and three points were selected under starved lubrication sliding: (1) 5 min after the oil cutoff, (2) the moment of variation state, and (3) the moment of dry sliding. In addition to the laser cladded coating and surface textured coating, gray cast iron was employed as a reference sample under the same tribotesting conditions.

The friction coefficient and sliding time were recorded automatically by a signal acquisition system. The worn surface was observed by SEM and EDS. The cross sectional profile and worn volume of the wear track were measured using CLMS. The results displayed in the paper are the average value of three samples.

\section{Experimental Results and Discussion}

\subsection{Characterization of Laser Cladded Coating}

Figure 5 shows the optical microstructure of the laser cladded coating at the cross section and the magnified morphology of different regions. The $\mathrm{Ni}-\mathrm{Cu}$ alloy layer and Fe-based coating adhered firmly to the gray cast iron and intermediate layer, respectively. A fusion line could be easily found between the adjacent claddings, and recrystallization occurred in the fusion zone, as shown in Fig. 5a. Along with the graded changes in the temperature gradient and solidification rate from the fusion zone to the coating surface, the microstructure exhibited a typical structural transformation sequence from planar crystals, cellular crystals, and columnar dendrite crystals to equiaxed crystals [16], as shown in Fig. 5b-d. The microstructure in the middle of the $\mathrm{Ni}-\mathrm{Cu}$ alloy layer exhibited a cellular structure, as shown in Fig. 5e. Figure $5 \mathrm{f}$ shows that the interface zone between the $\mathrm{Ni}-\mathrm{Cu}$ alloy layer and gray cast iron was characterized by tiny patches of retained austenite, acicular martensite, 


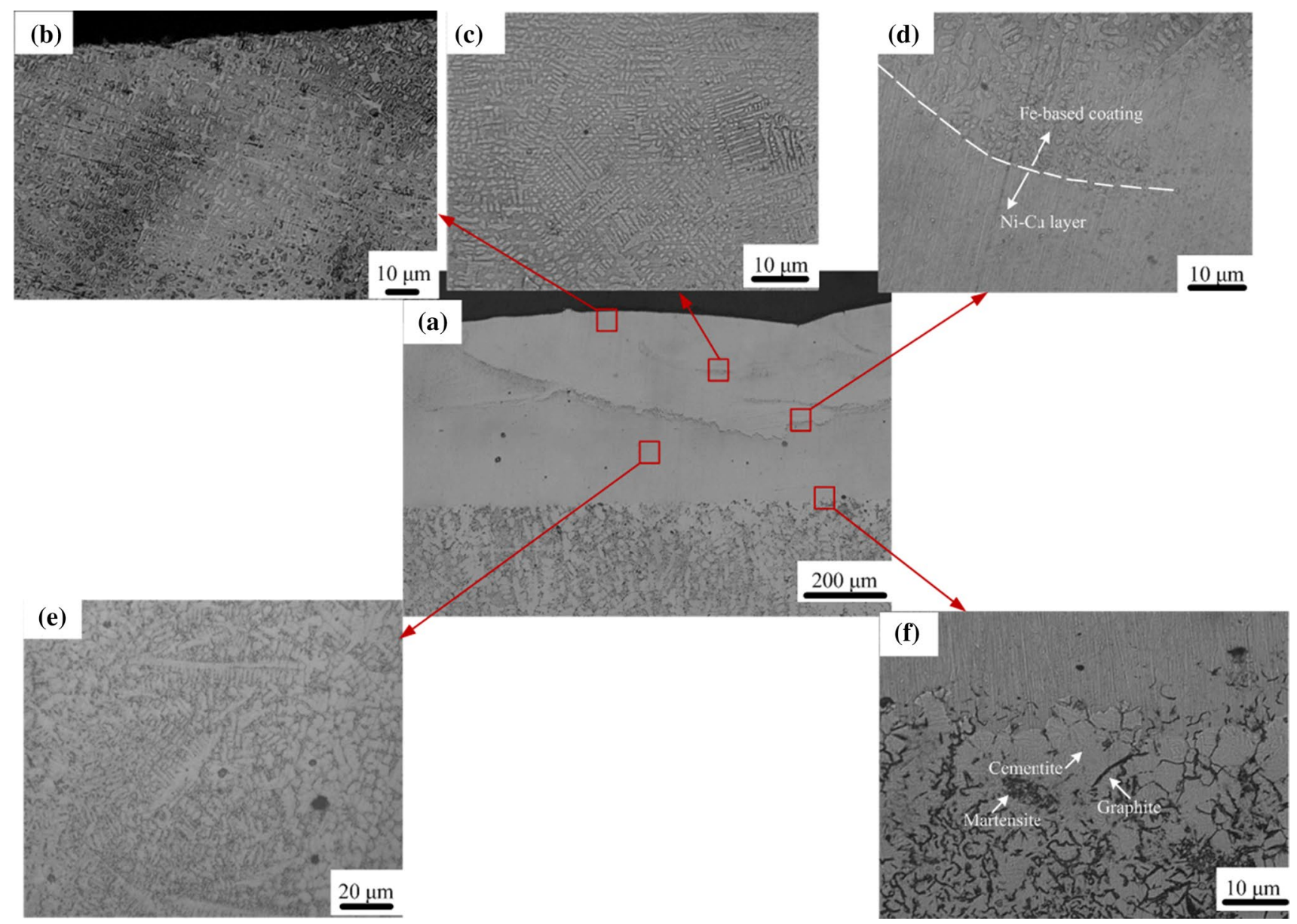

Fig. 5 Optical micrographs of the cross section of the laser cladded coating a, microstructure of the Fe-based coating in the upper layer $\mathbf{b}$, the middle layer $\mathbf{c}$, and the interface between the Fe-based coating

lamellar cementite and irregularly dispersed graphite. Similar results were reported in reference [17].

Figure 6 shows the X-ray diffraction patterns of the $\mathrm{Ni}-\mathrm{Cu}$ alloy layer and the Fe-based coating. Strong peaks of $(\mathrm{Ni}$, $\mathrm{Cu}$ ) solid solution phases can be easily found in the cross section of the intermediate layer, and it seems that there is no obvious appearance of carbides, as shown in Fig. 6a. The coating surface is mainly comprised of retained austenite $\alpha(\mathrm{Fe}, \mathrm{Ni}, \mathrm{Cr})$ and martensite $\left(\mathrm{Fe}_{1.91} \mathrm{C}_{0.09}\right)$, as shown in Fig. 6b. The bright interdendritic microstructure in Fig. 5b is probably the carbide; however, due to its small amount, there were no obvious peaks in the XRD results [18]. Moreover, the X-ray diffraction results reveal that the grain growth orientation in both laser cladded coatings was perpendicular to the substrate [8].

The overall elemental distribution at a cross section of the laser cladded coating is shown in Fig. 7. Elemental diffusion in the two almost flawless interface zones was not obvious. Due to the low solubility of carbon, the Ni-Cu alloy layer can prevent carbon migration from gray cast iron [17] and and $\mathrm{Ni}-\mathrm{Cu}$ alloy layer $\mathbf{d}$, microstructure of the $\mathrm{Ni}-\mathrm{Cu}$ alloy layer in the middle section $\mathbf{e}$, and in the interface between $\mathrm{Ni}-\mathrm{Cu}$ alloy layer and the gray cast iron $\mathbf{f}$

thus reduce chilled structure formation in the interface zone. Additionally, small amounts of $\mathrm{Cr}, \mathrm{Ni}$ and $\mathrm{Cu}$ in the $\mathrm{Ni}-\mathrm{Cu}$ layer diffuse into the substrate so that metallurgical bonding is formed [19].

Figure 8 displays the hardness profiles of the cross section in the laser cladded coating. The hardness distribution presents graded changes from the top coating surface to the substrate. The hardness underwent a smooth transition from the substrate to the Fe-based coating because the $\mathrm{Ni}-\mathrm{Cu}$ alloy layer serves as a buffer layer between the Fe-based coating and gray cast iron substrate [20]. The fluctuation in the Fe-based coating was more violent than that in the $\mathrm{Ni}-\mathrm{Cu}$ alloy layer, indicating that the former possessed a more uneven microstructure and grain size distribution than the latter. In addition, the hardness varied more sharply in the interface zone near the Fe-based coating than near the substrate. The external surface of the Fe-based coating possessed the highest hardness (approximately $727 \mathrm{HV}$ ), which was similar to that of the interface 

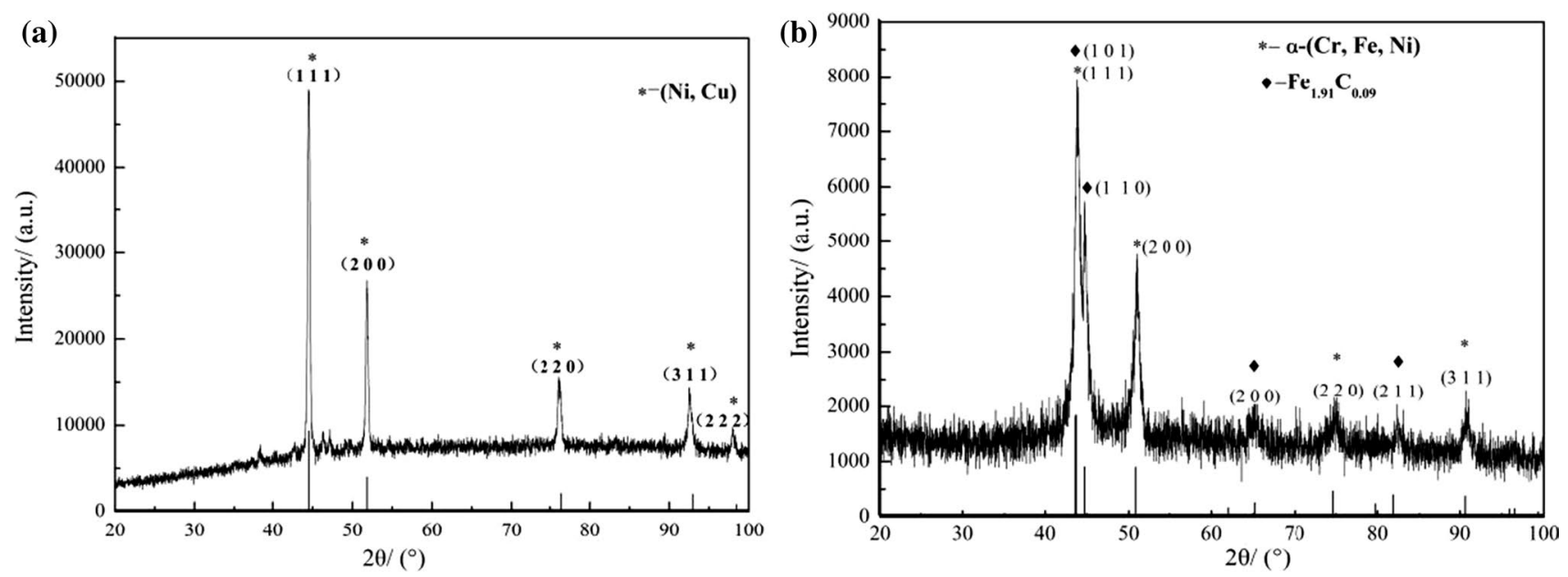

Fig. 6 XRD patterns of the Ni-Cu alloy layer $\mathbf{a}$ and the Fe-based alloy coating surface $\mathbf{b}$
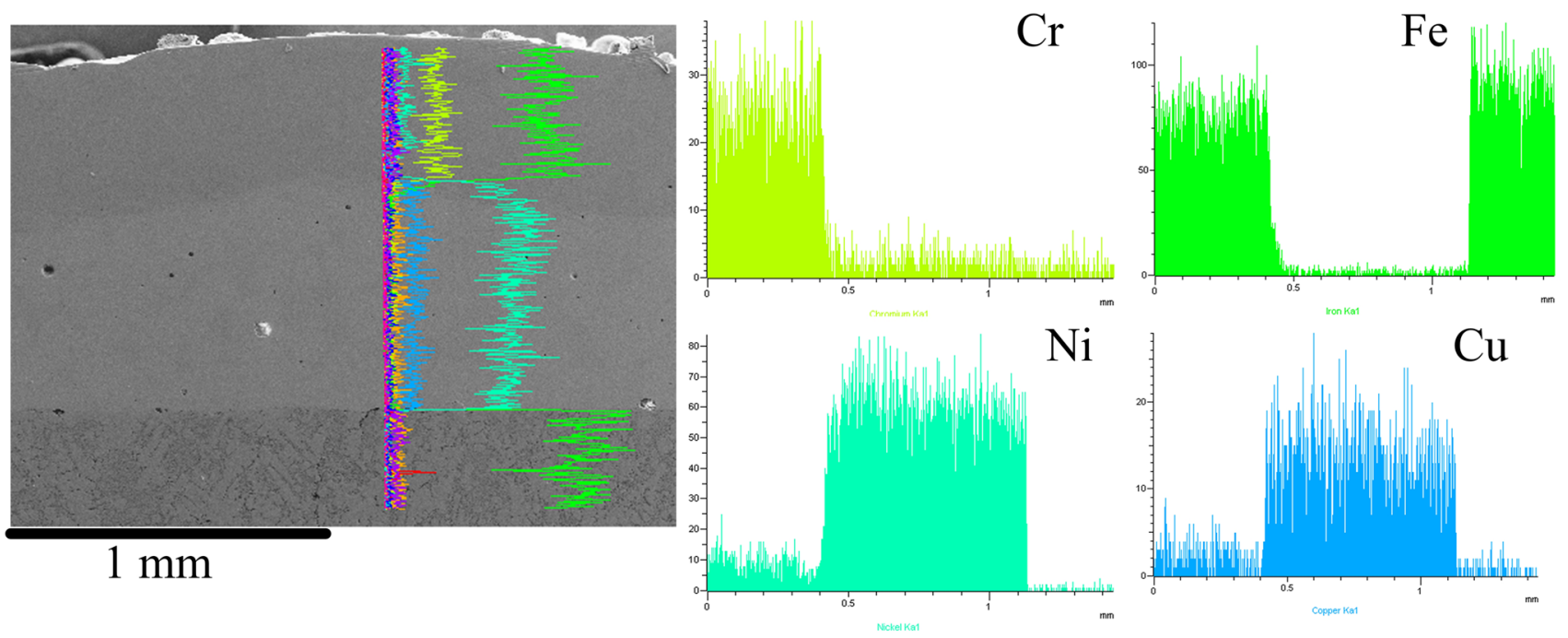

Fig. 7 EDS line scanning at the cross section of the laser cladded coating

zone between the $\mathrm{Fe}$-based coating and $\mathrm{Ni}-\mathrm{Cu}$ alloy layer. This is due to the formation of martensite in the Fe-based coating. The average hardness value in the intermediate layer was approximately $350 \mathrm{HV}$. The internal layers are subject to the in situ tempering effect of the subsequent layer in multilayer laser cladding [21], consequently resulting in the homogenous microstructure distribution in the intermediate layer in the present study. Therefore, a relatively low hardness in the intermediate layer and gradient hardness distribution in the cross section are beneficial for reducing the stress level within the laser cladded coating and preventing crack initiation and growth [4]. Moreover, this also helps improve the wear properties.

\section{Tribological performance under dry sliding}

The friction coefficient of the tested samples under dry sliding is shown in Fig. 9a. It is noted that gray cast iron took a comparatively long time to reach a stable friction coefficient, namely, a long running-in period. At the stable friction stage, the average friction coefficients of the laser cladded coating and gray cast iron were approximately 0.5 and 0.55 , respectively. The primary reason for the lower friction coefficient of the laser cladded coating is that the coating had a hardness that was three times higher than that of the gray cast iron. In general, materials with higher hardness possess excellent wear resistance, and the friction coefficient relates 


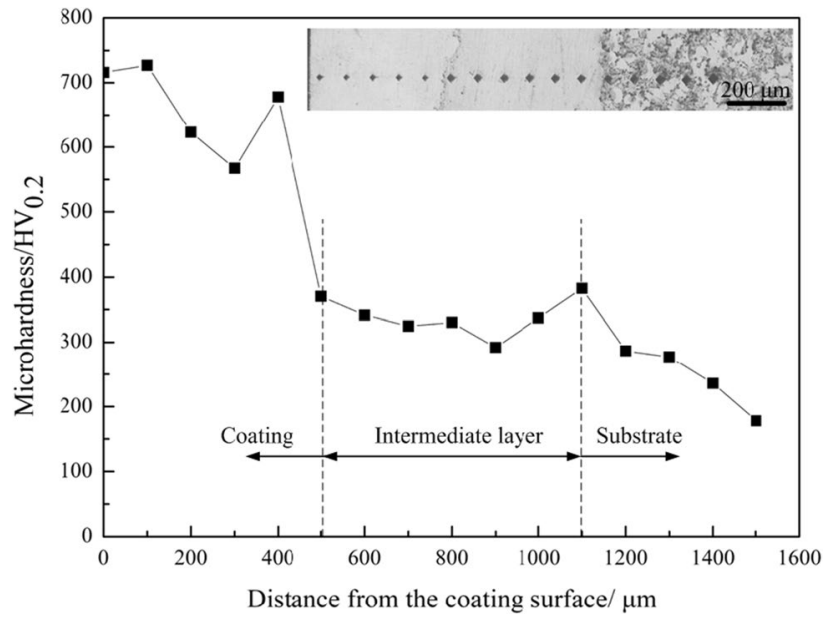

Fig. 8 Microhardness profile of the cross section of the laser cladded coating

to the hardness [22]. Due to its high content of graphite, gray cast iron showed superior tribological behavior [1], resulting in a relatively low friction coefficient under dry sliding conditions. Therefore, there is a limitation on the friction coefficient reduction by laser cladded Fe-based coating. Due to the presence of microdimple edges and nonconformal contact between friction pairs, the friction coefficient violently fluctuated in the initial test period and then gradually increased. The average friction coefficient of the textured coating stabilized at approximately 0.7. Slawomir et al. [23] found similar results under starved lubrication. The textured samples show a sharp increased friction coefficient at the beginning of the test, followed by a gradual decrease after reaching a peak value. The reason for this phenomenon is probably due to the change in the contact type from point to conformal as the friction process proceeds. It is worth noting that introducing microdimples possibly deteriorates the friction performance of the laser cladded coatings under dry sliding conditions.

It can be clearly seen in Fig. 9b that the gray cast iron shows the largest worn volume owing to its relatively low hardness. The average worn volumes of the untextured and textured coatings were 6 and 20 times lower than that of the substrate. It is evident that increasing the hardness can improve the wear resistance, and thus, a laser cladding $\mathrm{Fe}$ based coating can be applied to enhance the anti-wear properties of gray cast iron. Compared to the untextured coating, the textured coating possesses a 4 times lower worn volume, which is mainly attributed to the debris entrapment of textured microdimples.

After running-in, the worn surface of Fe-based coating presented a relatively flat wear track, and small patches of friction layers and shallow grooves existed on the wear track, as shown in Fig. 10a. The worn surface topography of textured sample after running-in are shown in Fig. 10b and c. It can be found that small amount of debris was entrapped in the microdimple and the edge of microdimple presented slightly plastic deformation along the sliding direction. Compared to the untextured coating, a thicker and rougher friction layer discontinuously attached on the textured coating. The results provide the evidence that the friction coefficient of textured coating fluctuated violently at the runningin stage than that of the untextured coating. For the gray cast iron sample (Fig. 10d), the delamination and plastic deformation can be observed on the wear track.

As shown in Fig. 11a, two discontinuous black friction layers tracks appeared on both sides of the wear scar, and a large amount of deformed adhesive layer existed on the laser cladded coating surface. In addition, the noticeable plastic rheology of the friction layer was along the sliding direction. The magnified view (Fig. 11b) is assumed to be the oxidized
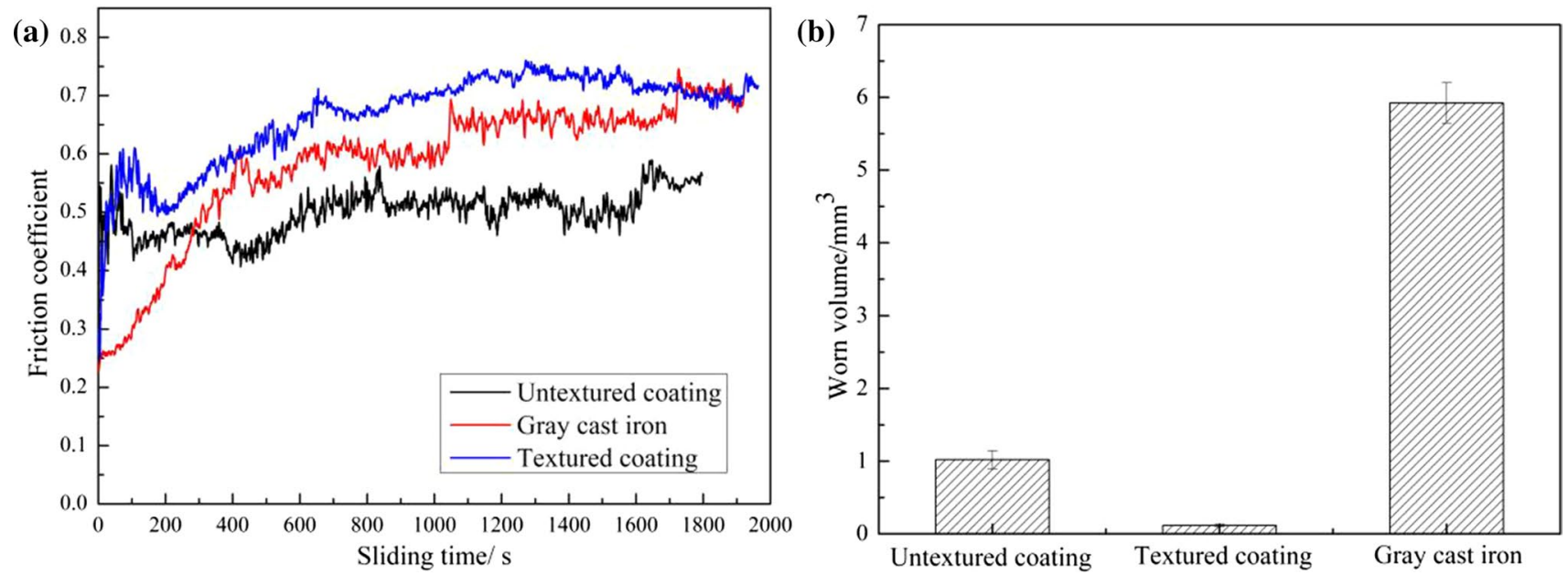

Fig. 9 Friction coefficient $\mathbf{a}$ and worn volume $\mathbf{b}$ under dry sliding 

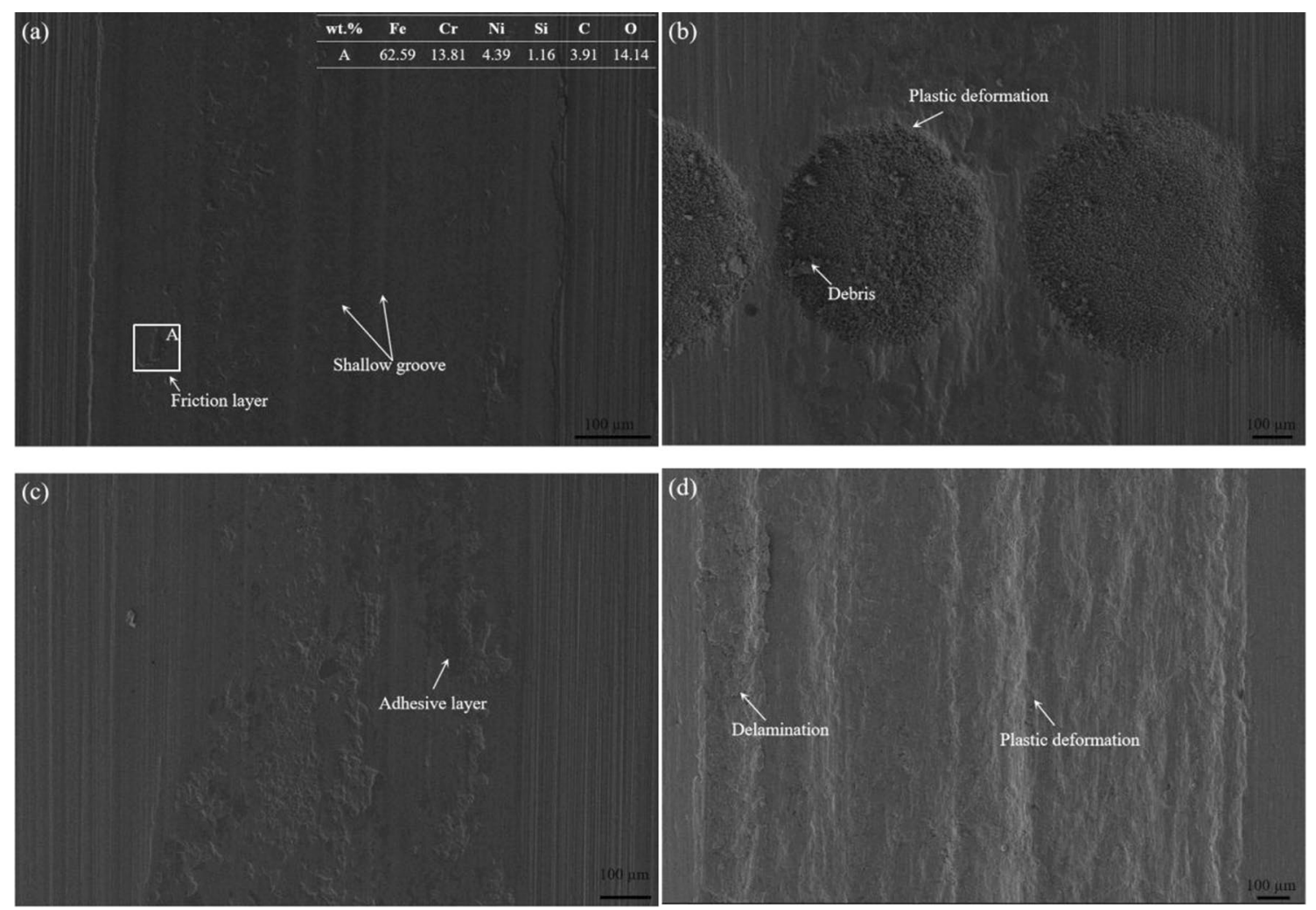

Fig. 10 Morphology of the worn surface after running-in under dry sliding of the laser cladded coating a, the textured as-deposited coating (b, c) and the gray cast iron $\mathbf{d}$

mechanical mixing layer (MML), which was formed by the extrusion and adhesion of debris [3, 24], and then the severe oxidation reaction was induced by friction heat. The worn surface of the untextured coating indicates that the main wear type was adhesive wear. The worn surface of the textured coating is shown in Fig. 11c and d. Owing to the nonconformal contact between the contacting pairs, the edges of the microdimples were repeatedly crunched by a counterpair ball, resulting in collapse and severe plastic deformation at the edges of the microdimples. Even under fully lubricated conditions, the presence of microdimple edges leads to degraded friction performance in nonconformal contact [25]. Small particle sizes of wear debris and patches of friction layers were scattered on the coating surface without microdimples. In contrast to the untextured coating, microdimple texturing has the effect of debris entrapment, resulting in a smoother friction surface. It is evident that the dominant wear mechanism of the textured coatings was light abrasive and adhesive wear. Figure 11e and $\mathrm{f}$ show the SEM images of the wear track for gray cast iron. Due to the self-lubrication role of graphite, a continuous friction layer was firmly attached to the surface of gray cast iron. However, owing to the low hardness of gray cast iron, noticeable grooves and delamination occurred on the wear track, indicating that severe abrasive and fatigue wear prevailed.

\subsection{Tribological Performance Under Starved Lubrication}

The friction coefficient of samples under starved lubrication is shown in Fig. 12a. It can be clearly seen that the friction process can be roughly divided into three stages: steady state (I), variation state (II) and dry friction (III). In stage I, the friction coefficient remained steady and low. The untextured coating showed the lowest friction coefficient in comparison to the textured coating and gray cast iron, approximately 0.13 . However, the textured coating was prone to maintain a steady state with a low friction coefficient for a relatively long sliding distance compared to the untextured coating and substrate. Entering Stage II, the friction coefficient increased with slight fluctuation and subsequently arrived at the dry friction value. The untextured and textured coating had a short sliding distance in the variation state, revealing that the transformation of the lubrication regimes occurred quickly. However, the variation state for the gray cast iron lasted for a relatively long sliding distance, and then dry friction ensued.

The worn volume of the tested samples under starved lubrication is shown in Fig. 12b. The textured coating showed the lowest worn volume $\left(0.74 \mathrm{~mm}^{3}\right)$, followed by the untextured coating $\left(1.11 \mathrm{~mm}^{3}\right)$, while the gray cast iron had the highest worn volume $\left(2.02 \mathrm{~mm}^{3}\right)$. It seems that the 
(a)
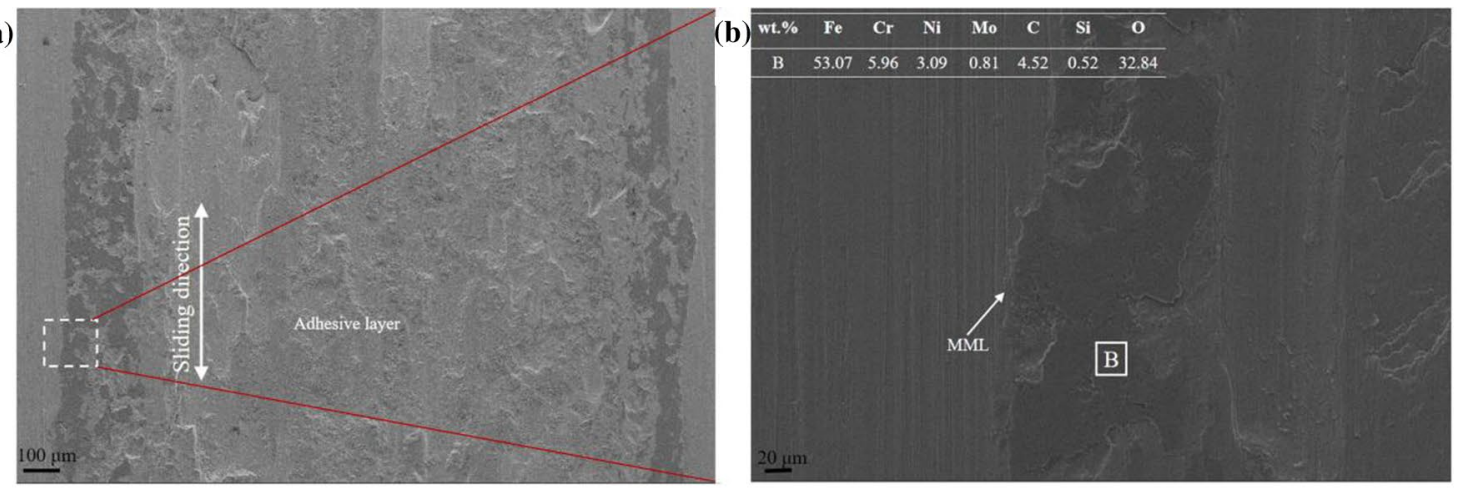

(c)
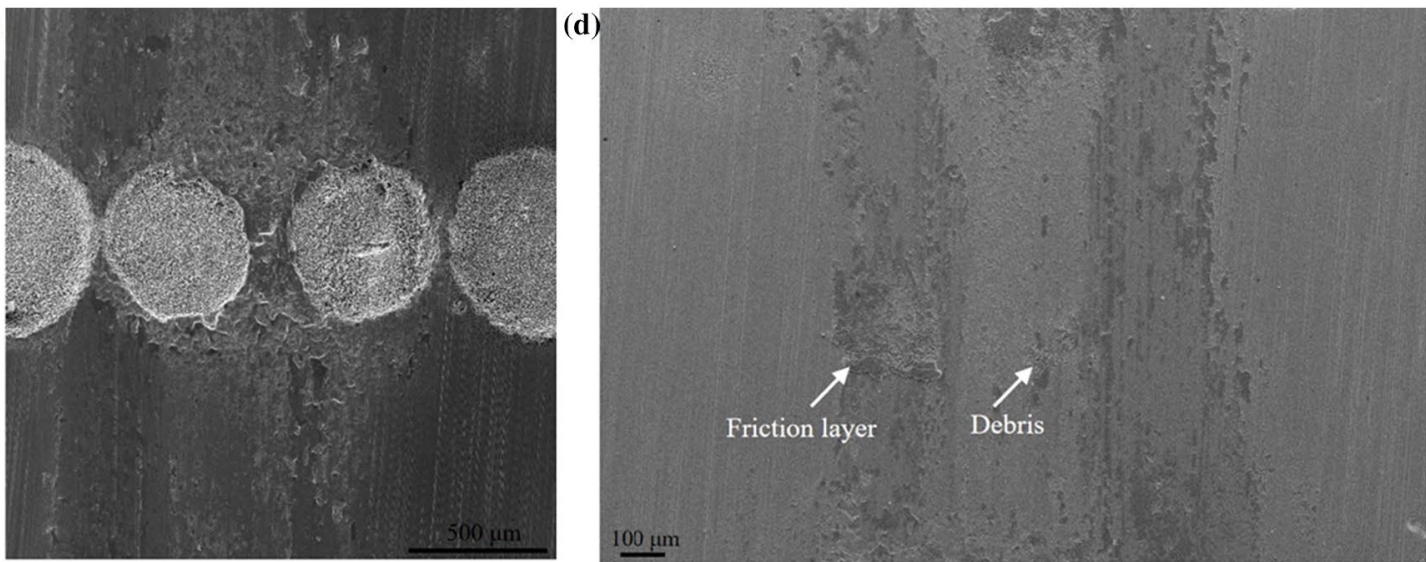

(e)

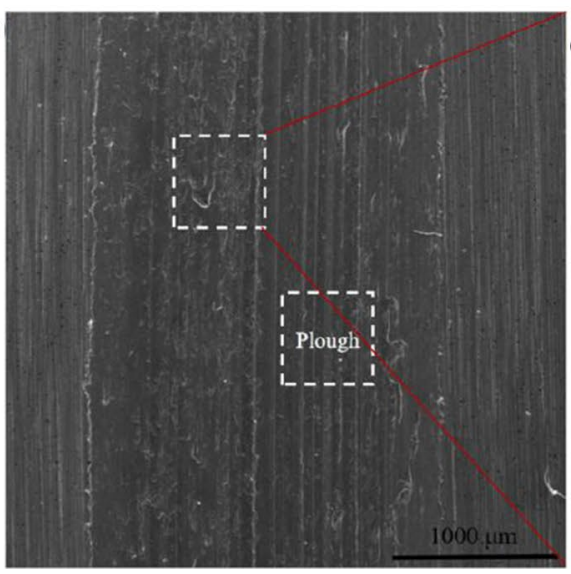

(f)

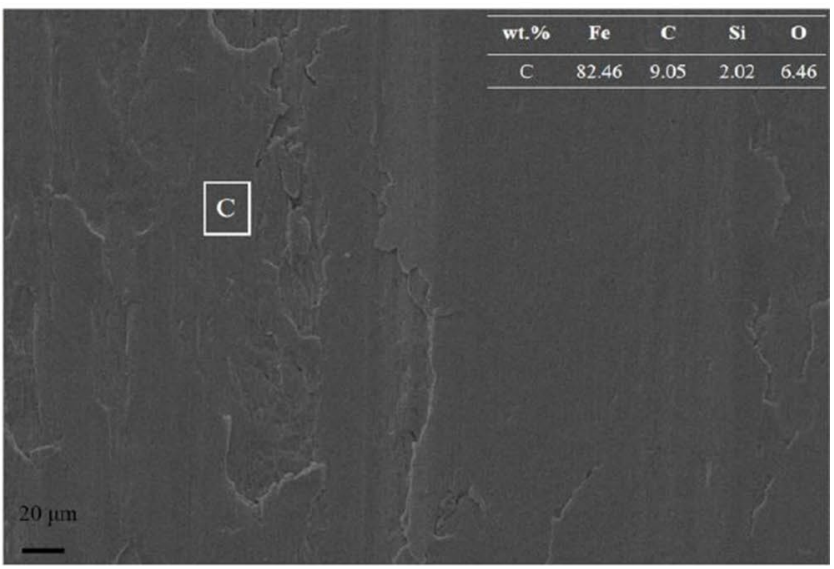

Fig. 11 Morphology of the worn surface under dry sliding and magnification of the laser cladded coating (a, b), the textured as-deposited coating $(\mathbf{c}, \mathbf{d})$ and the gray cast iron $(\mathbf{e}, \mathbf{f})$ at the end of wear tests

microdimple texture can improve the friction and anti-wear properties under starved lubrication.

As shown in Fig. 13a, a smooth wear scar and only small spots of black tribolayer are present on the untextured coating surface after the oil cutoff. For the textured coating (Fig. 13b), the microdimples along the wear track showed smaller dimension compared to the original one. The presence of the microdimple edge generated an intensification of the stress distribution [25], so that plastic deformation appeared firstly at the microdimple edge.
Although small amount of tribolayer are visible on the textured coating surface, the wear scar on the textured coating was much narrower than that on the untexture coating. Figure $13 \mathrm{c}$ gives the morphology of the worn surface of gray cast iron. The severe extrusion deformation can be seen on the gray cast iron, accompanied by the scattered particle debris.

Entering the variation state, due to the lack of lubricant on the untextured coating surface, spalling of the tribolayer occurred regionally and the light plowing was formed, as 

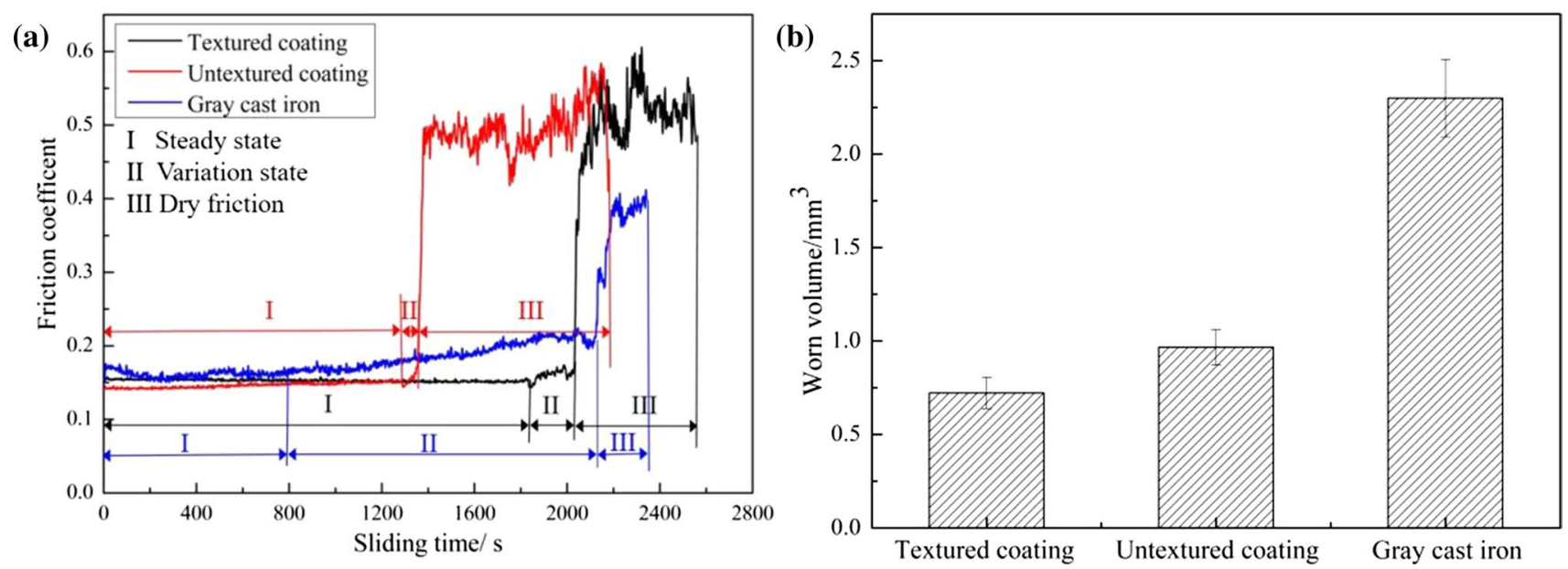

Fig. 12 Friction coefficient $\mathbf{a}$ and worn volume $\mathbf{b}$ under starved lubrication
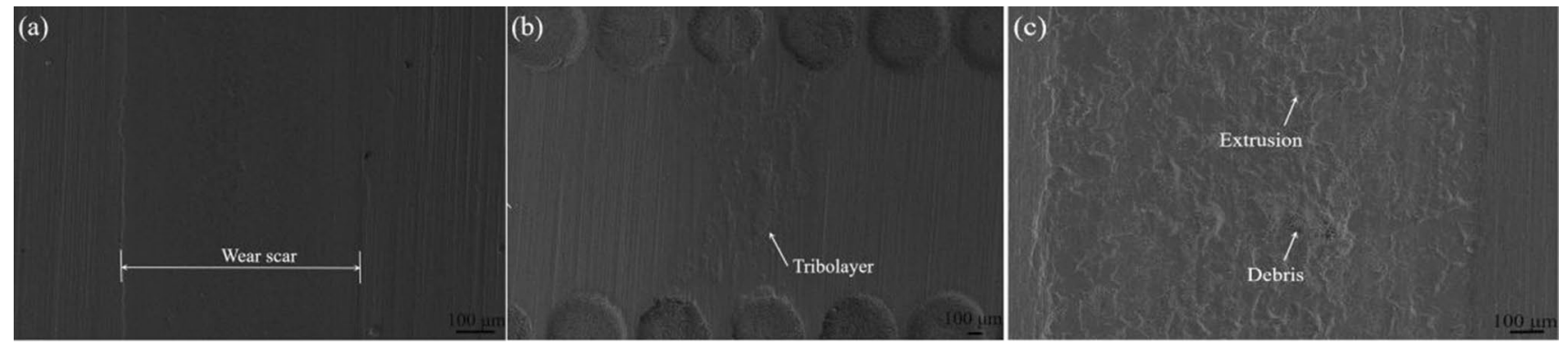

Fig. 13 Morphology of the worn surface under starved lubrication and a magnification of the laser cladded coating a, the textured as-deposited coating $\mathbf{b}$ and the gray cast iron $\mathbf{c}$ at the moment of $5 \mathrm{~min}$ after the oil cutoff
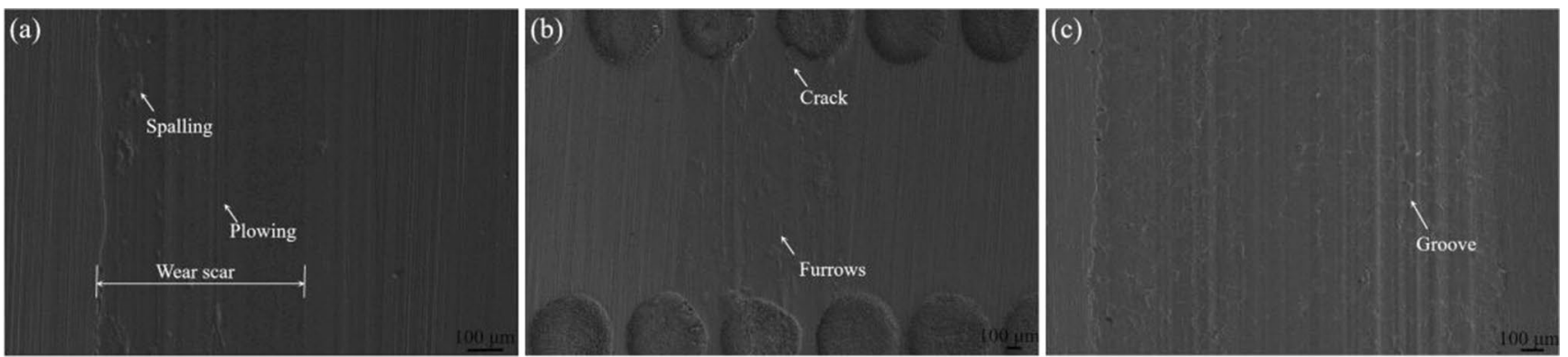

Fig. 14 Morphology of the worn surface under starved lubrication and a magnification of the laser cladded coating a, the textured as-deposited coating $\mathbf{b}$ and the gray cast iron $\mathbf{c}$ in the variation state

shown in Fig. 14a. The microdimples kept almost similar dimension compared to the previous friction stage (Fig. 14b). Moreover, the reciprocating loading caused the initiation of a micro-crack at the edge of microdimple. In addition, the wear track showed relatively flat and minor furrows on the untextured surface. The worn surface of gray cast iron sample was dominated by a compact and thick friction layer, and plastic plowing along the sliding direction, as shown in Fig. 14c.

Figure $15 \mathrm{a}$ and $\mathrm{b}$ show the worn surface topography of the untextured cladding coating at the end of wear test. It can be clearly seen that a continuous and dense friction layer attached to the coating surface. The energy spectrum result at point $\mathrm{D}$ indicates that a low content of $\mathrm{O}$ appears on the friction layer. Moreover, there was a large amount of spalling 
(a)
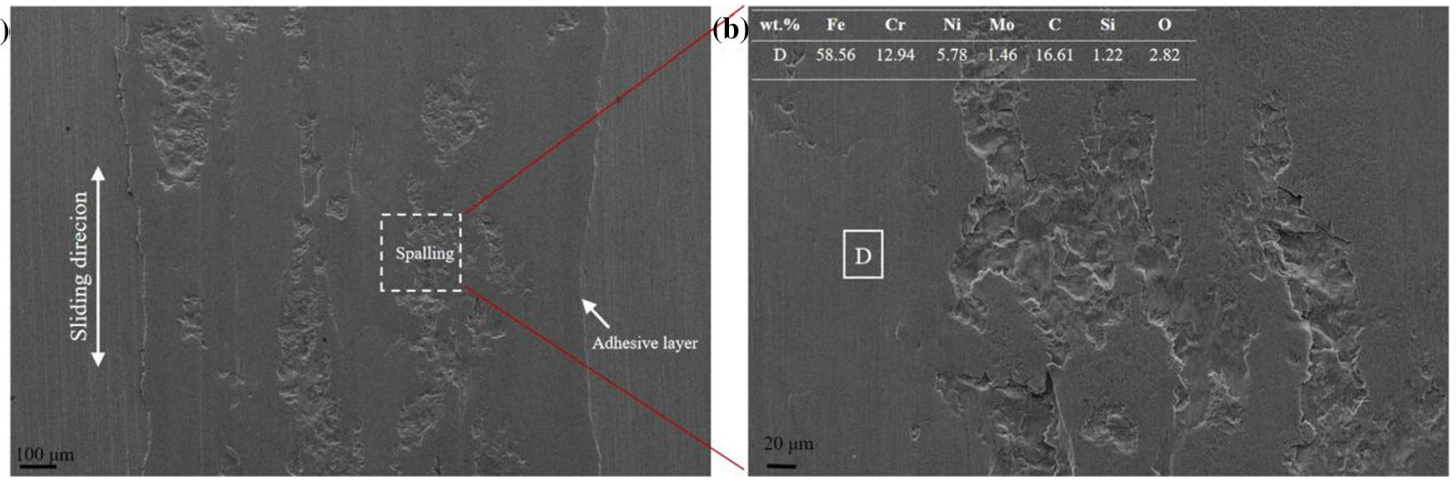

(c)
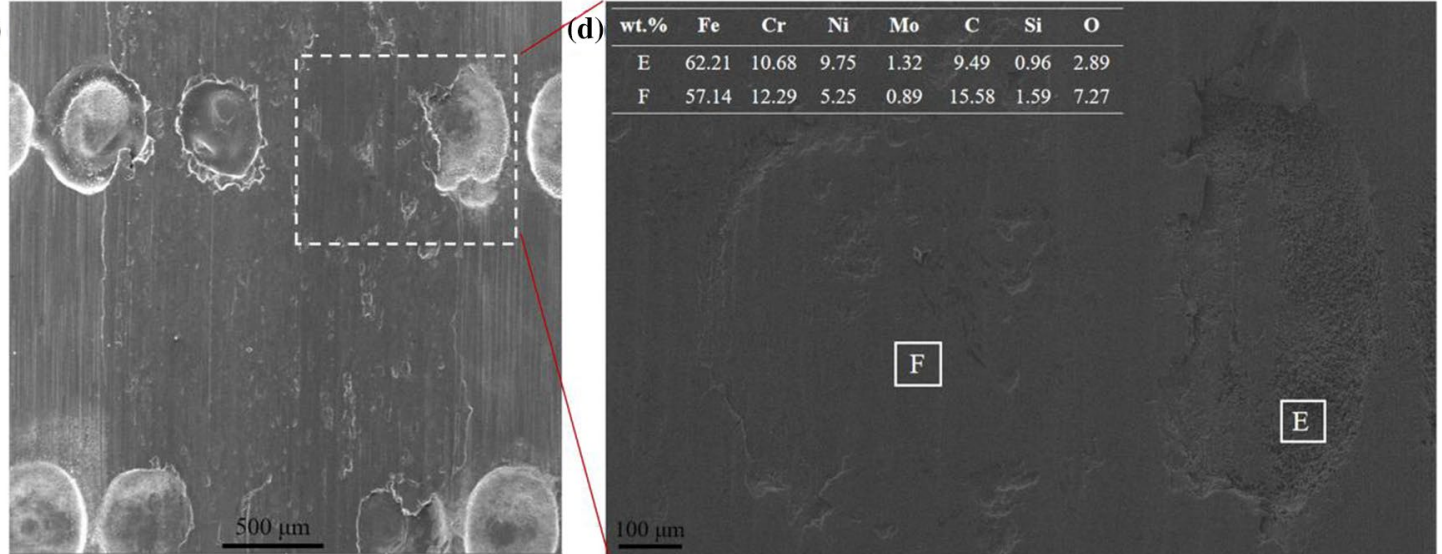

(e)
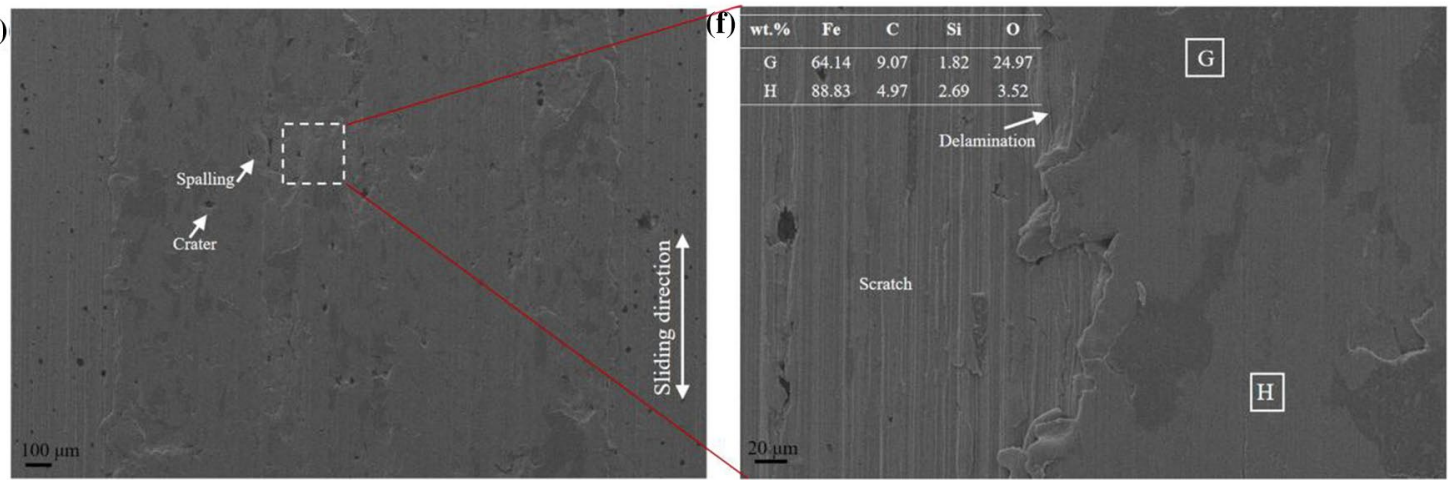

Fig. 15 Morphology of the worn surface under starved lubrication and a magnification of the laser cladded coating (a, b), the textured as-deposited coating (c, $\mathbf{d})$ and the gray cast iron $(\mathbf{e}, \mathbf{f})$ at the end of wear tests

on the friction layer, indicating that the tribofilm hindered the direct contact between the friction pair to reduce the coating wear [26]. The worn surfaces of the textured coating are shown in Fig. 15c and d. A flat and compact friction layer was attached on the surface without microdimples, accompanied by noticeable plastic deformation at the rim of microdimples. Additionally, some microdimples were filled with the wear product and became even. Because microdimples can provide secondary lubrication and trap debris and because the tribofilm forms on the specimen surface to protect the surface from metal-metal contact in starved lubrication [27], the textured coating can maintain a long time period of steady-state friction. However, as friction continued, the textured microdimples were worn out, and there was no effective lubrication. Consequently, the contact regime rapidly transferred to dry friction. A lot of heat accumulated at the contact area in a short time, which led to strong adhesion wear and oxidation of the surface [28]. The morphologies of the typical worn surface of the gray cast iron are shown in Fig. 15e and f. Severe wear with several craters and a coarse surface can be observed. Because gray cast iron contains large graphite, graphite flakes can be easily peeled off due to their low strength, resulting in craters [1]. Additionally, a scattered oxidation film with a 
high oxygen content adhered to the surface of gray cast iron, revealing that oxide reactions occur during the friction process. Furthermore, after oil film depletion, a large friction layer area peeled off, and obvious scratches occurred on the fresh metal matrix. This wear surface damage characteristic will lead to a large worn volume.

\section{Conclusion}

(1) The multilayer coating was laser cladded on gray cast iron. The $\mathrm{Ni}-\mathrm{Cu}$ alloy layer is used as an intermediate layer to hinder carbon migration and reduce the formation of a chilled microstructure. The Fe-based alloy was coated on the $\mathrm{Ni}-\mathrm{Cu}$ alloy layer and served as a surface coating. Microdimples were created by REJP on the as-cladded coating.

(2) The morphology of the cross section of the laser cladded coating showed that there were no cracks or crevices in the $\mathrm{Ni}-\mathrm{Cu}$ layer/substrate or in the $\mathrm{Ni}-\mathrm{Cu}$ layer/ Fe-based coating interface zone, and the shapes and growth orientation of dendrites depended on the heat transfer direction. The EDS results indicate a small amount of element diffusion occurred at the boundaries, which was beneficial for maintaining the nominal elemental composition of the alloy coatings. The microhardness profile further revealed the graded distribution of the microstructure.

(3) Laser cladded coatings slightly decreased the friction coefficient compared to gray cast iron under dry sliding. However, due to the presence of the sharp edges of microdimples in the contact region, the textured coating showed a deteriorated friction performance. Both untextured and textured coatings exhibited noticeably lower wear track volumes than the gray cast iron. Additionally, owing to the debris entrapment effect, the textured coating presented a smoother worn surface than the untextured coating.

(4) After the lubrication oil was discontinued, the microdimple textured coating maintained a steady friction state with a lower friction coefficient for a longer time period; this result is attributed to the oil reservoir and debris entrapment of the microdimples. When the microdimples were worn out, the friction coefficient increased sharply. The textured coating showed excellent anti-wear performance under starved lubrication. Additionally, the laser cladded coating exhibited better tribological performance than gray cast iron.

Acknowledgements The authors appreciate financial support from the National Natural Science Foundation of China (grant number
51605066), the Liaoning Province Natural Science Foundation (Grant Number 2020-HYLH-22), the Chinese Postdoctoral Science Foundation (Grant Number 2020M670734), and the Fundamental Research Funds for the Central Universities (Grant Number 3132019366).

Funding National Natural Science Foundation of China, 51605066, Jing YU, Natural Science Foundation of Liaoning Province, 2020HYLH-22, Jing YU, Chinese Postdoctoral Science Foundation, 2020M670734, Jinlong WANG, Fundamental Research Funds for Central Universities of the Central South University, 3132019366.

Open Access This article is licensed under a Creative Commons Attribution 4.0 International License, which permits use, sharing, adaptation, distribution and reproduction in any medium or format, as long as you give appropriate credit to the original author(s) and the source, provide a link to the Creative Commons licence, and indicate if changes were made. The images or other third party material in this article are included in the article's Creative Commons licence, unless indicated otherwise in a credit line to the material. If material is not included in the article's Creative Commons licence and your intended use is not permitted by statutory regulation or exceeds the permitted use, you will need to obtain permission directly from the copyright holder. To view a copy of this licence, visit http://creativecommons.org/licenses/by/4.0/.

\section{References}

1. Q. Li, Y. Zhang, Y. Zhang, H. Liu, H. Ren, Y. Zhong, X. Huang, W. Huang, Appl. Phys. A 126, 282 (2020)

2. K. Masuda, N. Oguma, M. Ishiguro, Y. Sakamoto, S. Ishihara, Wear 474-475, 203870 (2021)

3. H. Liu, J. Liu, J. Hao, H. Yang, X. He, G. Yu, JOM 72, 4281 (2020)

4. Y. Li, S. Dong, P. He, S. Yan, E. Li, X. Liu, B. Xu, J. Mater. Process. Tech. 269, 163 (2019)

5. J.M.S. de Sousa, F. Ratusznei, M. Pereira, R. de Medeiros Castro, E.I.M. Curi, Tribol. Int. 143, 106002 (2020)

6. Y. Li, S. Dong, S. Yan, X. Liu, E. Li, P. He, B. Xu, Opt. Laser Technol. 112, 30 (2019)

7. A. Mulone, A. Nicolenco, N. Imaz, V. Martinez-Nogues, N. Tsyntsaru, H. Cesiulis, U. Klement, Coatings 9, 66 (2019)

8. Y. Li, S. Dong, S. Yan, E. Li, X. Liu, P. He, B. Xu, Mater. Charact. 151, 273 (2019)

9. Y. Li, S. Dong, S. Yan, X. Liu, P. He, B. Xu, Opt. Laser Technol. 108, 255 (2018)

10. S. D. Sun, D. Fabijanic, M. Annasamy, S.C. Gallo, I. Fordyce, A. Paradowska, M. Leary, M. Easton, M. Brandt, Wear 438-439, 203070 (2019)

11. E.M. EI-Banna, M.S. Nageda, M.M. Abo EI-Saadat, Mater. Lett. 42, $311(2000)$

12. X. Wang, J. Liu, Y. Wang, Y. Fu, Appl. Surf. Sci. 396, 659 (2017)

13. P. Lu, R.J.K. Wood, Surf. Topogr.: Metrol. Prop. 8, 043001 (2020)

14. Y. Shen, B. Ye, B. Yu, Z. Liu, R. Huang, J. Xu, Surf. Coat. Tech. 408, 126806 (2021)

15. Y. Shen, Y. Lv, B. Li, R. Huang, B. Yu, W. Wang, C. Li, J. Xu, J. Mater. Process. Tech. 266, 329 (2019)

16. K. Li, J. Liang, J. Zhou, Surf. Coat. Tech. 423, 127520 (2021)

17. Y. Li, S. Dong, S. Yan, X. Liu, P. He, B. Xu, Surf. Coat. Tech. 347, 20 (2018)

18. P. Yang, Y. Song, J. Wang, F. Hu, L. Xie, Weld. World 65, 785 (2021)

19. J. Liu, H. Liu, X. Tian, H. Yang, J. Hao, J. Alloy. Compd. 822, 153708 (2020) 
20. Y. Liu, F. Weng, G. Bi, Y. Chew, S. Liu, G. Ma, S.K. Moon, Int. J. Adv. Manuf. Tech. 105, 4097 (2019)

21. H. Liu, J. Hao, Z. Han, G. Yu, X. He, H. Yang, J. Mater. Process. Tech. 232, 153 (2016)

22. H. Tan, Z. Luo, Y. Li, F. Yan, R. Duan, Y. Huang, Wear 324-325, 36 (2015)

23. S. Wos, W. Koszela, P. Pawlus, P. I. Mech. Eng. J-J. Eng. 229, 398 (2014)

24. Viswanatha B.M., M. Prasanna Kumar, S. Basavarajappa, T.S. Kiran, Ind. Lubr. Tribol. 70, 818 (2018)

25. G.S. Joshi, C. Putignano, C. Gaudiuso, T. Stark, T. Kiedrowski, A. Ancona, G. Carbone, Tribol. Int. 127, 296 (2018)
26. Y.-X. Zhou, J. Zhang, Z.-G. Xing, H.-D. Wang, Z.-L. Lv, Surf. Coat. Tech. 361, 270 (2019)

27. F. Saeidi, M. Parlinska-Wojtan, P. Hoffmann, K. Wasmer, Wear 386-387, 29 (2017)

28. Y. Niu, X. Pang, S. Yue, B. Shangguan, Y. Zhang, Wear 476, $203723(2021)$

Publisher's Note Springer Nature remains neutral with regard to jurisdictional claims in published maps and institutional affiliations. 